\title{
Literature Review of Contract Grading for Multilingual and ESOL Writing Classes
}

\author{
A Capstone submitted to the faculty of \\ San Francisco State University \\ In partial fulfillment of \\ the requirements for \\ the Degree
}

Master of Arts

In

English: Teaching English to Speakers of Other Languages

\section{Peter Kevin VanValkenburgh \\ San Francisco, California}

May 2021

Faculty Advisor: Priyanvada Abeywickrama, Ph.D. 


\section{Copyright by}

Peter Kevin VanValkenburgh 


\title{
Literature Review of Contract Grading for Multilingual and ESL Writing Classes
}

\author{
Peter Kevin VanValkenburgh \\ San Francisco, California \\ 2021
}

This literature review explores contract grading, an alternative to traditional grading, from its history, briefly, to its current application, addresses the nuances of design and application, and considers how it might be applied to native English, TESOL, or multilingual writing classes. Contract grading is frequently advanced out of a desire to be more fair and equitable to students with grading, or in some instances, to advance a teacher's political or ideological stance. The pros and cons of these approaches are discussed in this paper as are the implications of stances taken toward language dialects, codes, jargons, or styles used to teach and assess college writing. 


\section{Acknowledgements}

I would like to thank Dr. Abeywickrama for her help as my advisor in completing this capstone, and Dr. Santos my capstone English 895 class professor. I would like to thank all of my professors at San Francisco State University for their instruction and guidance during graduate school, and all of my peers. 


\section{Table of Contents}

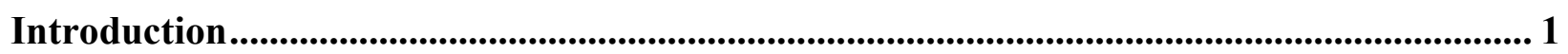

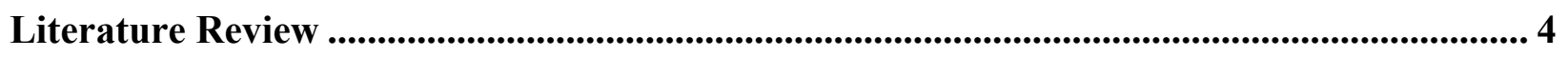

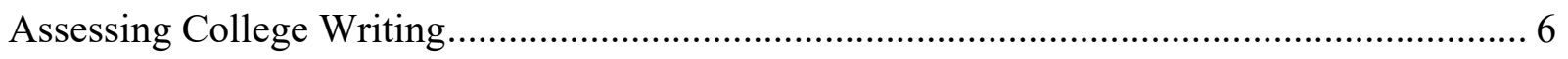

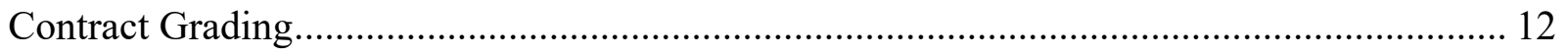

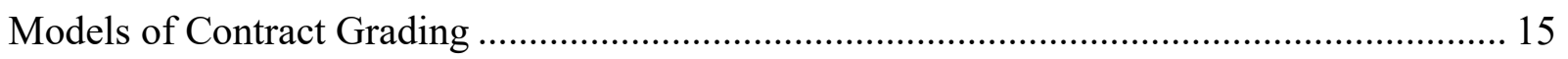

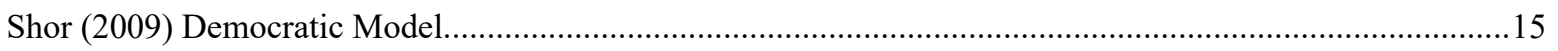

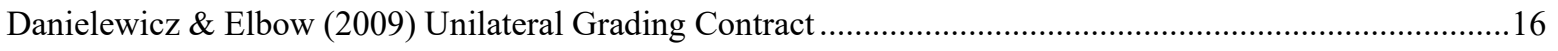

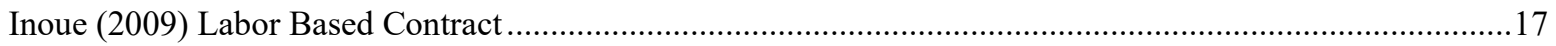

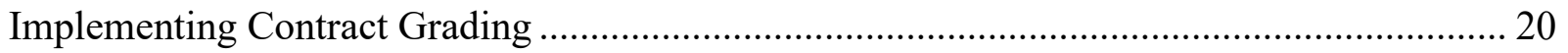

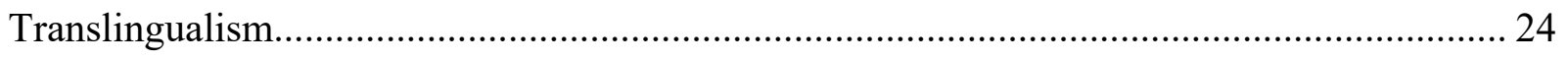

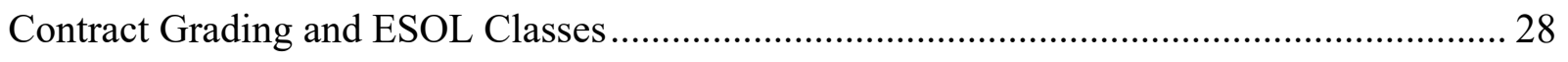

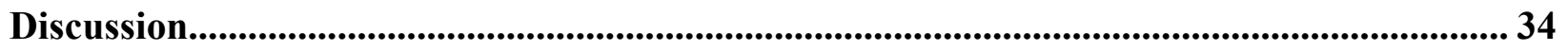

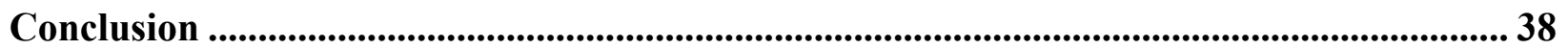

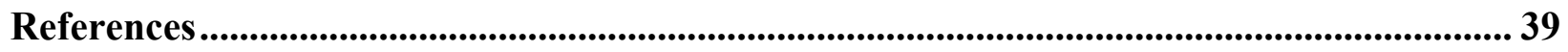




\section{Introduction}

This capstone paper considers contract grading as an assessment strategy for college writing students pursuing English for Academic Purposes (EAP) and its relevance to Teaching English to Speakers of Other Languages (TESOL). Contract grading, which is usually understood as an alternative to traditional grading, is receiving considerable attention in academic discussions and is gaining popularity as it is adopted by new and existing writing teachers, particularly in the field of Composition. Although a primary focus of this paper is TESOL, the discussion that follows is relevant to the teaching of writing across the disciplines and embodies ideas that span the disciplines of writing, rhetoric, and composition. We explore how the advantages and benefits of contract grading realized in composition and other disciplines might apply to writing for TESOL. These include various concepts and ideas that promote fairness that are also applicable to students who are English Speakers of Other Languages (ESOL), a term that will be used throughout this paper. We hope to explore and contrast contract grading with similar concepts related to TESOL. While there is ample literature on contract grading in the field of composition, contract grading is less robustly discussed in TESOL contexts. Thus, we explore similar ideas and concepts related to contract grading such as grading, labor contracts, and learning contracts and discuss their relevance to student agency, fairness and equity, which further lead us into questions of the role of the individual and groups with respect to assessment. This paper hopes to help further this discussion of contract grading in TESOL contexts by focusing on and discussing common issues that apply to the teaching of writing and we hope to encourage others to consider contract grading for academic writing instruction. The issues explored herein are of particular relevance today since college writing 
classes are much more diverse than they were, say, fifty years ago, and collectively, the students we teach speak many varieties of English as well as other languages.

With this in mind, we approach contract grading with some assumptions about contemporary writing classrooms, For instance, the assumption that ESOL students' learning needs are to a great extent shared in common with the needs of native English speaking students, and that it makes contract grading valuable for writing instruction (Cox, 2014). This includes not only similar academic needs, such as the ability to write persuasively, but also the affective needs of students related to fairness and equity concerning decisions about style, dialect use, and language varieties. In addition, similar needs with respect to decisions about learning that concern issues affecting culture, ethnicity, and race, and also issues related to the subjectivity and reliability of grade norming (Shor, 2009; Danielewicz \& Elbow, 2009; Inoue, 2016, 2019; Schwarz, 2020). Moreover, we consider how contract grading may be beneficial when teachers decide that a process stance to writing is a preferred method for students to achieve greater writing proficiency (Elbow, 2006; Danielewicz \& Elbow, 2009). A term that is coming to represent a modern recognition of the reality about the way we use language is translingualism, which will be discussed later.

My interest in assessing college writing has grown and intensified since the Fall semester of 2019 when I taught a first-year writing course to mostly freshman and sophomore students at SFSU. The students in this class represented students of diverse native English dialect and language backgrounds and included at least one ESOL student. While developing the curriculum for this class, I struggled, as many teachers do, with the topic of assessment, as fairness in 
grading and assessment are frequent topics of discussion amongst writing teachers. Moreover, quite a few of my graduate teaching assistant peers adopted contract grading as central to their assessment practice and chose not to grade students based on an evaluation of their writing, opting instead to grade attendance, labor, and participation related to writing. I, on the other hand, settled on a hybrid grading scheme that incorporated elements of contract grading, such as low-stakes ungraded pass/fail reading and writing assignments, with three major essay assignments that were graded more traditionally. Each draft of the major essay assignments received feedback from classmates and/or myself, and the students' final draft received a letter grade of between ' $\mathrm{A}$ ' and ' $\mathrm{C}$-', assuming students met the basic requirements of the writing assignment in the form of a rubric, which they helped co-create. I chose to issue letter grades on these writing assignments with the idea that I would use the grades to motivate students to revise their essay, and I gave them an opportunity to revise each essay throughout the semester for a higher grade. Students had the opportunity to revise their main essays and increase those grades with no time limits or penalties, and a substantial number of students did so. Despite this success, I struggle with whether my assessment strategy could be better, and I have become increasingly interested in diving in and examining the pedagogical arguments for and against contract grading, and also in studying how other teachers apply contract grading. I am further interested in learning from any empirical research or other studies that explore and elaborate the benefits, or problems, associated with contract grading, especially for multilingual learners. Therefore, this capstone represents, in part, an attempt to further my understanding of contract grading, generate a discussion of contract grading in TESOL, and an undertaking that helps me formulate future assessment strategies for teaching academic writing, whether in composition or TESOL. 


\section{Literature Review}

To accomplish the goals of this capstone, I have set out to review the literature for contract grading, so it would be useful to start with a brief introduction of contract grading followed by a review of the history of assessment in writing. One way to think of contract grading is as a method of assessment where a teacher forges an agreement with their students that to earn a specified grade, they must accomplish a specific set of tasks for that grade, A typical example from the 1960s or 70s might approximate this description by Yarber (1976):

The contract system determined grades by a contractual agreement, established in advance and signed by the student, which stipulated in detail the quantity and quality of work that must be completed to earn the chosen grade. This evaluation method was also frequently called contract-for-grade method, learning contract, student contract, contract method, and contract learning method. (p. 11)

More contemporarily, contract grading, might be best explained as an alternative to traditional forms of grading that takes numerous forms, and that often moves teachers away from issuing letter grades that evaluate the quality of the students' writing, and instead, favors issuing grades

for completing tasks or doing other labor in the classroom; however, moving away from grades is not a requirement of contract grading (Shor, 1999, 2009; Danielewicz \& Elbow, 2009; Inoue, 2015, 2019; Schwartz, 2020). Another reason that the use of contract grading might be attractive to teachers is related to difficulties of assessing in light of how standards for what constitutes good writing change based on numerous contextualized reasons for writing, as well as the variety of lenses from which one might assess writing quality (Shor, 2009; Danielewicz \& Elbow, 2009; Elbow 2006; Inoue, 2019). For instance, the rhetorical purpose, the audience, and other factors that influence the genre of writing are important contextual factors for evaluating writing, and so 
is an understanding of the students' dialect and language use backgrounds (Gee, 2012). Given that there are many different ways to assess the quality of writing, ranking and issuing grades on student writing can also be complicated by its inherent subjectivity; for example, no two evaluators are likely to come to the exact same conclusion on writing quality. This is not to suggest that student writing should not be evaluated, but it requires that we think deeply about how and why we are assessing student writing, both philosophically, and practically, while in the process of evaluating their writing. To better understand this in context, it might help to first look at a brief history of writing assessment. 


\section{Assessing College Writing}

The history of assessing college writing can be divided into three overlapping waves from approximately 1950 to the end of the 20th century. In the first wave, assessment attempted to be objective, standardized--via a technology of testing, and in line with testing theory. Writing assessment focused largely on grammar and usage, and employed methods such as multiplechoice exams (Yancey, 1999). The second wave of assessment saw more of a focus on individual essays, and assessments started to be more concerned with the writer, as opposed to objective measures of the text. Assessment practices then moved from assessing the discreet essay to assessing multiple drafts, and to portfolio assessment. In the third wave of writing assessment, the role of self-assessment and the social dimension became more recognized and a pedagogy of assessment emerged that is much more self-conscious (Yancey, 1999). Since the turn of the new century, one can argue that a fourth wave has emerged with a focus on fairness and equity, and an awareness that the evaluation of writing to some degree constrains, or even shapes, the writer. Though this awareness is not new, there is a renewed emphasis to address these constraints of evaluation and assessment. In addition, there has long been a move to decenter or even to eliminate grades for assessment in writing (Kohn, 2013), in part, because grades and evaluations include judgments about cultural beliefs and assumptions that affect identity (Huot, 2002). Nevertheless, others still feel that writing assessment is an important and necessary part of the way we teach writing (Huot, 2002; Martin \& Penrod, 2006; Shor, 2009; Elbow, 2006)). Furthermore, our writing, and our students' writing is and will continue to be evaluated at some level, for instance by society, other academics, and future employers (Martin \& Penrod, 2006). 
Thus, decisions on whether to evaluate students' writing quality for grades or whether to base grades on some other criteria are important topics for discussion as there are many complexities surrounding assessing college writing. To consider this further, it is appropriate to discuss in more depth some of the problems with traditional grading.

The ranking and grading of students, generally, has been called into question by many researchers (Kohn, 2013; Inoue, 2019), and the grading of academic writing has been criticized for numerous reasons since at least the early 20th century (Yarber, 1973; Taylor, 1971, 1980). Early on, criticisms of grades were often related to questions surrounding the teachers' ability to apply universal standards to writing, also known as grade norming, due to the inherent subjectivity of writing assessment. Additionally, some stakeholders questioned the utility of grading as a means to further the development of students' ability to learn to write well, which was sometimes associated with producing good citizenship (Taylor, 1971, 1980; Shor, 2009; Kohn, 2013). More recently, although the early criticisms remain, increasingly, grades are criticized for cultural, racial, and linguistic reasons (Shor, 2009; Danielewicz \& Elbow, 2009; Inoue, 2014, 2019; Gee, 2012; Schwarz, 2020). This criticism is in part due to the changing demographics of American society over the last half-century, and also due to advances in the understanding of language in all its varieties, the proliferation of global communities, and the spread of cultural pluralism. The role of technology and the internet is another factor that is rapidly changing our society and the way that we think about things (Haidt, 2012). The results of these recent technological influences on language, writing, culture, and society are yet to be fully realized. 
Considering how our society and the world is changing, the ways that we understand assessing and grading student writing is, or perhaps, should also be changing, which suggests that we need to consistently reassess and rethink our assessment practices and their relationship to fairness, equity, and the needs of students, both inside and outside of the academy. The idealism of teachers needs to be balanced against the needs and desires of students. Especially since assessments and grades can impact students in numerous ways, such as those that impact their identity, which include considerations of their self and culture, race, ethnicity, or other aspects of identity such as choice of major and future occupation. Identity, in the news lately often as unidimensional or intersectional, is a much more complex psychological concept that includes multiple layers and sophisticated intersectionality. One way to define Identity is "as the set of possible meanings of roles in the form of expectations of others for one or more of these possible meanings [multiple selves]. They require that the meanings be internalized by actors" (Brenner, Serpe, \& Stryker, 2014, p. 232). Moreover, how we grade students can affect their selfesteem and motivation towards school work, and it is important to remember that grades have a gatekeeper function that affects students' ability to be accepted or enrolled into subsequent classes, programs, schools, and grades may eventually impact their occupations. Thus, grades can be quite consequential for students, and for ESOL students there are special considerations around assessment due to what may be unique challenges. For instance, many scholars argue that applying a specified native English standard to ESOL students is unfair, and as problematic as standards may be for native students of different dialect backgrounds, it can be particularly unfair when applied to the academic writing of ESOL students (Cox, 2014; Madura, 2014; Lee, 2016). This point is well made by Cox (2014): "second language acquisition is a long process 
and that native-like writing cannot, and should not, be the goal. In fact, many of us consider it to be unethical to demand native-like (or error-free) writing from L2 students" (p. 308). Others, like Inoue, $(2015,2019)$ argue more strongly that evaluating writing based on a standard academic English dialect is racist and is promoting white supremacy. However, since the terms "racist" and "white supremacy" carry several different connotations in our society, whether one agrees with Inoue, or not, common sense suggests that grading students from different language backgrounds by any single dialectal standard likely has the effect of privileging some students and disadvantaging others. Consequently, thinking of language through translingual approach may help us appreciate the reality that language is ever-changing and negotiable since the translingual approach recognizes these complexities of language (Horner, Lu, Royster \& Trimbur, 2011; Matsuda, 2014; Lee, 2016):

We call for a new paradigm: a translingual approach. This approach sees difference in language not as a barrier to overcome or as a problem to manage, but as a resource for producing meaning in writing, speaking, reading, and listening. (p. 303)

Thus if and whether we evaluate students' writing quality for grades, The role of grades impacts students' writing differently. Surely, many of us can relate to Schwarz (2020) who in discussing contract gading recalls her undergraduate writing experience: "Good writing meant following rules. Good writing was figuring out what the teacher wanted and adjusting accordingly before you were scolded" (p. 2). The rules of good writing might not only include rules of grammar or style but also might include attempts to write in such a way as to please the teacher's intellectual, social, or political preferences. As a result, we risk students orienting their writing toward the goal of earning a grade and attempting to please the teacher, rather than 
writing as part of an intrinsically motivated intellectual pursuit, or, perhaps, to explore the limits of their creativity. These qualities are the sort that would excite me as a writing teacher! Therefore, many agree with Inoue (2019), when he says grading, "is a distraction that pulls students away from the real dialogues and discussions about their writing that we want to have" (p. 5). This distraction from the process of writing seems to be a recurring theme of many teachers and scholars who claim that the process is often subordinated by the students' desire to earn high grades, and this is a primary motive of Danielewicz and Elbow (2009). However, there are other teachers and scholars that advocate political resistance to grading based on assertions of racism, power differentials, or even criticism of capitalism, sometimes as part of a doctrine referred to as "critical theory," which seems to be short for "critical social theory" (CST) (Shor, 2009; Inoue, 2014, 2019). The policy of injecting politics and sociology into writing pedagogies have produced some interesting discussions. For instance, Danielewicz and Elbow (2009) in a discussion, appears to both praise and critique the critical theory focus, a focus that they do not embrace:

They [CST] seek to authorize students to take as much control as possible over their lives as individuals and as a community. Many important course policies like attendance and workload are worked out through class votes and mutual negotiation with the teacher. Seeking not just to democratize the classroom but in fact to work against the ideology of capitalism and class privilege, Shor and his colleagues have turned to contract grading as one method. We will compare their uses of contracts and goals with ours. There are striking differences, yet we also feel some comradeship. (p. 245)

Another criticism of traditional grading concerns itself with linguistics, or the study of the way that we use language, in and beyond the classroom. These criticisms are largely concerned with how teachers apply a dominant standard, code or dialect of language to students who grow up 
with different levels of exposure to these dialects. In particular, in response to standard academic dialects (SAD), or Standard American English dialects (SAE), to which they are often referred. The concern is that these dialects privilege students with familiarity to these standard or academic dialects of English, for instance, middle class students whose parents graduated from colleges and may speak the dialect in the home (Gee, 2012). On the one hand, Inoue (2015, 2019) has argued that grading often imposes a standard that is based on the habitus of the teacher and the institution, which according to Inoue, is a system predicated on "White supremacy." Thus, whether or not you agree with how he labels the problem, his concern that grading reflects a standard (dialect or genre) that may not be native to many of the students in the writing class, and particularly, students of color is compelling, and so it follows that if this is true for native English speakers of different backgrounds, then this understanding can be extended to ESOL students who may also be disadvantaged from an adherence to a single dominant dialect or code of English. Nevertheless, these choices are complicated, as not teaching the dominant language codes have also been argued to disadvantage students (Shor, 2009; Lee, 2016). Many favor embracing a more flexible approach toward language dialects or codes, and believe that the inherent flexibility of contract grading enables us to remedy these and other considerations around grading, as opposed to traditional grading, since contract grading can take into consideration the differing needs of students and apply multiple strategies. 


\section{Contract Grading}

Contract grading, as an alternative to traditional methods of grading, has been discussed in academic circles since the early part of the twentieth century (Yarber, 1973, p. 22); however, the practice of contract grading gained considerable popularity during the late 1960s and 1970s as teachers again started to question the status quo around traditional assessment practices (Taylor, 1971, 1980; Hart, 1975). Then, during the 1990s, a renewed interest in contract grading emerged in the teaching of writing (Shor, 1999, 2009; Danielewicz \& Elbow, 2009; Inoue, 2015, 2019; Schwartz, 2020), and this interest has continued into the new millennium as a number of teachers and scholars started adopting and writing about contract grading for reasons associated with, among others, an emphasis on social justice, often attached to critical social theory (Shor, 1999; Inoue, 2015; 2019; Schwarz, 2020). More recently, contract grading is increasingly associated with critical race theory (Inoue, 2015, 2019; Schwarz, 2020), which should be understood as more narrowly focused on race. Additionally, there has been a substantial interest in contract grading outside of writing instruction as contract grading has been explored in a variety of other academic subjects, for instance: including, but not limited to, mathematics, health, history, and psychology (Yarber, 1973; Hart, 1975; Lindemann \& Harbke, 2011; Mullen, 2020), and apart from any sociological, political, or ideological attraction to contract grading, its popularity for its emphasis on "process writing" in writing classrooms has remained a long standing and important motivation in its own right. This is due, in large part, to the substantial influence of Peter Elbow, and of Danielewicz and Elbow (2009) who emphasize that one of the main values of contract grading is its emphasis on the actual practice, or process of writing, as opposed to the emphasis on grades (pp. 241, 261). Contract gradings flexibility and some of its 
challenges can be illustrated through a discussion of different teachers and scholars models of contract grading.

Schwarz (2020) evaluated 132 writing teachers who were using contract grading in an attempt to better understand the practice of contract grading, in part, by examining contract grading as an assessment genre. Schwarz found that many of the teachers she interviewed, similar to that of my peers, modeled their contract grading strategies after either Shor (2009), Danielewicz and Elbow (2009), or Inoue (2019). Schwarz (2020) recognized the need for a more robust investigation of the key questions surrounding contract grading, which include questions such as: How are teachers implementing contract grading? What precisely is contract grading? And, how effective is contract grading? In an attempt to answer similar questions, Lindemann \& Harbke (2011) investigated the effectiveness of contract grading by comparing otherwise identical psychology courses, which compared contract grading alongside the same curriculum that used a traditional grading scheme, and they found some qualified benefits to contract grading, for instance, related to motivation and learning, but the benefits were not universal amongst students. Schwarz (2020) also found mixed results, and in an example to the contrary, discusses a teacher who found it harder to motivate students with contract grading "This teacher is concerned with a similar kind of resistance associated with a lack of motivation. In these cases, removing the grade, according to these responses, removes students' incentives for doing the required work of the course, like revisions (p. 54). Additionally, Inoue (2019), who is mostly positive about using contract grading, discusses how there are some students who are resistant to not being graded traditionally, suggesting that this is in part due to their familiarity with traditional grading. Thus, it is important to understand that adopting contract grading is not a 
panacea, and it may require that students become more familiar with it in the classroom for it to be successful.

Shor (2009), Danielewicz and Elbow (2009), and Inoue,s (2019) contract grading models come up for discussion frequently when discussing contract grading, and one of these three models are often adopted or modified by new teachers thinking about assessment, and by experienced teachers seeking to change from their traditional assessment practices (Schwarz, 2020). While exploring their models It is useful to examine and consider what each of these share in common, and also what they separately hope to accomplish through their different strategies. For instance, generally, each contract seeks to set out an agreement between the teacher and their students on what is expected in the classroom, what are the roles of the teacher and the students, what are the course expectations, and how any interim or final grades are applied to the students' work. Their contracts may differ in the specified amount of labor, or time, that students are required to put into their writing, or their work and activities may require a set word length or pages of writing to be completed. These contracts may also include things like attendance, participation, or other requirements for the course. Each type of contract and the components of that contract may offer certain advantages to students, but they each may also present their own challenges to students as should be evident as these contract grading models are explained in the next section. 


\section{Models of Contract Grading}

\section{Shor (2009) Democratic Model}

Starting with Shor's (1999) contract grading model, philosophically it is influenced by critical theory, and Shor also describes his model as one modeled with democracy in mind (2009, p. 14). Shor teaches his students about democracy by example, and thus, heavily involves his students in the participation of the decision-making process concerning what they choose to write about and how they will be graded. Shor (2009) negotiates the terms of the grading contract with his students, who act in their role as co-creators of their grading contract: "I hand out during the first class a teacher's proposed plan for earning A, B, and C grades, and invite students to negotiate both the grading proposals and the larger syllabus ..." (page 9). In addition, students play a major role in determining the subject of class writing, and they are asked to choose subjects related to current events, which tend to be political in nature, on which the students then vote (Shor, 1999, p. 2). However, in response to criticism implying that he pushes politics on students, Shor (2009) distinguishes the fact that although he is quite political in his scholarly writings and discussion with other teachers, he does not "preach" politics to his students, which he feels would be wrong. Thus, he not only allows students to pick the topics, but Shor (2009) also allows students the freedom to take whatever political stance they desire in their writing:

I don't lecture students (except for the rare practice of "the dialogic lecture," which I described in Empowering Education, 1992). I don't address students about the need to resist capitalism, which would be an abuse of my position. Lecturing or sermonizing students will silence many and encourage others to mimic. (p. 20-21) 
He also takes a nuanced pragmatic stance on teaching standard academic dialects, or Standard Written English (SWE), that some other scholars are pushing back against, giving the following justification: "Those few undergraduates en route to graduate or professional schools do need SWE, research writing, and exposure to belles-lettres so they can read closely as well as display the cultural capital required to circulate among professionals (Shor, 2009, p.10-11). Shor's (2009) model captures what many may perceive to be an influence from the 1960s and 70s social movements that were so influential at the time, with a strong focus on liberal democracy and pluralism.

\section{Danielewicz \& Elbow (2009) Unilateral Grading Contract}

Danielwicz and Elbow (2009) offer students what some scholars have termed a "hybrid grading contract," one they call a "unilateral grading contract" based on a strategy developed from years of teaching a process stance of writing. In this model, students can earn up to a "B" letter grade on the basis of completing the assignments as detailed in the contract, which includes requirements of attendance and tardiness with other requirements, without concern for the quality of the students" writing. However, to earn an "A" grade, Danielewicz and Elbow (2009) have chosen to evaluate the quality of the student's writing. Therefore, although students can earn a " $\mathrm{B}$ " for a final class grade if they meet all the writing and other requirements of the class, regardless of judgements about quality, to earn an “A," Danielewicz and Elbow (2009) expect something in their writing that is "excellent" and stands apart (p. 254). They acknowledge that there is a subjective quality to determining what is excellent writing and satisfy themselves by admitting that this overall process is imperfect, which they justify thus: 
But when students do "no more than" fulfill the contract requirements, the amount of work is actually quite gratifying to a teacher. We may get less strain-clench-struggle effort — and certainly less panic_-but we usually get a solid amount of work, even if some of the papers are definitely weak.

(Danielewicz \& Elbow, 2009, p. 256)

Danielewicz and Elbow mainly focus on writing as a process, and seek to remove as many distractions to writing as possible:

The bottom line is that contract grading fosters a deep commitment to process. If we seek to use physical exercise for health or fitness, the message from experienced people is the same: just keep going through the motions; trust it; it's the process that counts. William James famously argued that actions are not caused by emotions or beliefs; rather, actions lead to emotions or beliefs (p. 261).

\section{Inoue (2009) Labor Based Contract}

Inoue's (2019) version of contract grading, in contrast to the others, is based primarily and almost wholly on the amount of labor the students produce (p. 74), along with grading for attendance and tardiness. He does not grade individual papers or issue a final grade based on judgments about the quality of the student's writing. He does give extensive qualitative feedback from himself and students' peers. His contract, like Shor's (2009) is negotiated with his students:

A labor-based grading contract is essentially a set of social agreements with the entire class about how final course grades will be determined for everyone. These agreements are articulated in a contract, a document, that is negotiated at the beginning of the term or semester, then reexamined at midpoint to make sure it is still fair enough for everyone. It is a social, corporate agreement, which means it may not be a product of full consensus, but instead hard agreements. (Inoue, 2019, p. 30)

Inoue $(2015,2019)$ has taught writing using contract grading and evaluated students of White, Minority, and ESOL backgrounds at the community college, state, and university level with 
varying, but mostly positive results. Furthermore, Inoue has studied assessment practices rigorously, and he has given race considerable attention in his own assessment practices and in his scholarly writing. Ideologically, Inoue's assessment strategy embraces critical theory, and he labels it "Antiracist." Antiracist or Antiracism, as used by Inoue (2015, 2019), is a highly ideological and controversial term, and thus means something more than simply being 'anti racist' (against racism) (see McWhorter, 2021). In contrast to Shor's (2009) broad democratic appeal to critical theory, Inoue $(2015,2019)$ employs a critical theory lens that is more directly focused on critical race theory, which in part, is influenced from his personal experiences with racism as a mixed race person. and his perceptions of racism growing up in Las Vegas, Nevada (p. 16). Thus, in some regards, Inoue (2019), approaches writing instruction with a more explicit political and sociological mission: "And so, labor-based grading contracts is a big part of the methods I use to enact my social justice agenda in my classroom's antiracist writing assessment ecologies" (p. 16). However, Inoue (2019) also embraces a much more agreed upon linguistic opposition to grades, as he feels that students shouldn't be held back based on the code or dialect of English that they embody:

What I'm saying is that designing fair and meaningful grading practices is about cultivating with our students an ecology, a place where every student, no matter where they come from or how they speak or write, can have access to the entire range of final course grades possible. (Inoue, 2019, p. 3)

Interestingly, Inoue (2019) acknowledges that his pedagogy is paradoxical (p. 306), as his own success is tied to adopting a "white supremacist" habitus, which, by habitus, he describes as linguistic bodily, and performative dispositions (p. 5). Inoue $(2015,2019)$ clearly considers and embraces both the complexities and paradoxes of his pedagogical stances. Moreover, his political 
approach to assessment has been the focus of considerable attention in the last year or so, in part, due to the tragic death of an African American, George Flloyd, who died at the hands of Minneapolis police officers in 2020, and from which protests erupted that coincided with more than a year of a coronavirus pandemic (Covid-19) that highlighted the 2020-21 academic year. In concluding this section, it is worth noting how these scholars differ from each other. For instance, Shor (2009) is the only one of the three who grades every paper based on an evaluation of the student's writing quality, which he grades on a scale from A - F (p. 7).

Additionally, Shor (2009) differentiates what he terms his "democratic model" from Danielewicz and Elbows' (2009) which he refers to as "a business model:

A 'contract' requires 'a meeting of the minds,' that is, a covenant of explicit understanding between all parties affected by the terms. In this construction, no contract exists if one party unilaterally obliges another to abide by terms to which the second party did not formally consent" (Shor, 2009, p 13).

Elbow (2006) differs from the others, but especially Inoue (2004) as he explains the multiple approaches to assessing student writing that he articulates, which includes an approach that acknowledges an appreciation of social constructivism (community-based), but he also elaborates an appreciation for the variation among groups (both in-groups and out-groups), and also elaborates an appreciation for the individual writer. This approach he distinguishes from Inoue's (2004) community-based assessment model which appears to be more focused on the group's assessment, entailing a more specific social constructivist epistemology:

We would simply refrain from forcing them to agree on one set of criteria or one rubric. As a result, they would probably end up with a small or large handful of sets of criteria or rubrics: perhaps quite a few students would agree on one standard; then a few smaller groups would agree on different standards; and there might be a number of loners who do 
not agree with anyone else. (Of course it is possible, some semesters that the whole class might come to agreement in the absence of any rule that forces them to do so.). (Elbow, 2006, p. 91)

By contrast, Inoue's $(2004,2019)$ community-based assessment concept involves the class creating a single community rubric. In contrast, Elbow (2006) highlights how the individual writer might sometimes be in tension with a socially constructed sense of what constitutes good writing as he prefers to embrace and appreciate both stances. A final area where Danielewicz and Elbow (2009) differs from both Shor and Inoue is in how they do not embrace critical social theory in the classroom. Although, they acknowledge the inherently political nature of writing, they explicitly try to avoid politics, maintaining a primary focus on the writing process:

Our approach would appear to be highly unpolitical and "uncritical"-ideologically unaware. For our goal is to create a classroom where both teachers and students get to give as much time and attention as possible to writing — not to politics and culture. (Danielewicz \& Elbow. 2009, p. 241).

Each of these scholars has a unique stance for both the role of politics, or ideology, in the classroom, and each has their own unique ideas about how to evaluate writing and whether and how to apply grades. In common, they have each deeply considered the perplexity of issues involved in assessing grades, and they have embraced contract grading.

\section{Implementing Contract Grading}

Now that we have explored and contrasted different contract grading models, and examined the ways that these models are both similar and different, the next step is to consider how to implement a new or existing contract grading strategy. The different ways that teachers might design and implement contract grading can vary broadly and it may depend on the 
academic discipline, the type of class and subject being taught, the class level, and the requirements of an academic institution. Teachers may also need to take into consideration the role and desires of other stakeholders. Additional factors that influence the design of contract grading is the teacher's teaching philosophy and their unique approach to curriculum design. As noted previously, this includes the teachers' opinion toward whether to evaluate the quality of writing and whether and when to attach grades to students' writing. As noted previously, some teachers who use contract grading, like Shor (2009), evaluate the quality of writing and issue grades on the writing as part of a feedback mechanism. Thus, when planning to implement contract grading, it is not sufficient to understand contract grading as simply pertaining to whether to evaluate and issue grades for students' writing quality. Similarly, though some teachers are motivated by political, sociological, and ideological considerations associated with race, equity, or other aspects of identity, it is also not sufficient to understand contract grading as requiring any particular ideological, sociological, or political foundation (Taylor, 1980;

Danielewicz \& Elbow, 2009; Schwarz, 2020), In fact, existing contract grading practices span many ideologies and pedagogies, and it is worth repeating that some teachers resist or seek to depoliticize the classroom (Danielewicz \& Elbow, 2009; Elbow, 1999, 2006; Schwarz, 2020). A teacher seeking to implement contract grading has enormous flexibility to tailor their model to fit virtually any context.

So then, if contract grading does not require that we grade the quality of writing, or require that we have a specific ideological motive, then what does it require? On the simplest level, one might argue that virtually every class employs contract grading since most classes set out certain intrinsic expectations between teachers and students, whether those expectations are 
understood explicitly or implicitly, and though contract grading in its simplest form may be understood as a contractual agreement between a teacher and students, it appears that the difference is in the understanding that contract grading exists as an alternative to traditional grading practices (Taylor, 1978; Shor, 2009; Danielewicz \& Elbow, 2019; Inoue, 2019; Schwarz, 2020). The models previously discussed highlight three major considerations around contract designs. For instance, in one form, the teacher designs the contract largely according to their preexisting determination, creates at least most of the contract unilaterally, and then asks students to consent to the teacher's design. The second model of contract grading is created through mutual negotiation between the teacher and their students resulting in a contract where student participation in the design is considerable. and the third contract grading model represents some combination of these methods, a degree of unilateral and mutual design (Shor, 2009; Danielewicz \& Elbow,2009; Inoue, 2014, 2019; Schwarz, 2020).

In considering the practice of negotiating contracts, from my experience as a student, I have observed teachers who negotiate contracts with the students, and, notably, these negotiations tend to last until the teacher's essential requirements are met. In some instances, students, while citing criteria, tend to create a more rigorous and difficult contract, beyond what the teacher intended to offer. In short, negotiations may continue until some minimal criteria that the teacher desires is proposed and included in the final agreement. In other words, teachers can keep the negotiation in process until it reaches a conclusion that is satisfying to the teacher. This may include some coaxing by the teacher, i.e.: What about including a requirement for "readability"? In some cases, this begs the question of whether, in practice, a teacher guides their students during negotiation toward an agreement that is more or less similar to how one would 
appear if it was a unilateral contract, like Danielewicz and Elbow's (2009) contract?. This is not necessarily a value judgment about this process, but it is something teachers should take into consideration when implementing a design. Nevertheless, despite any tendency for the final design to approximate the teacher's preconceived will, students can have some real input into the final contract and this process can offer students a number of benefits pedagogically. At the very least, a contract with the students may help the students feel that they have buy-in, or a commitment to the contract by virtue of their input into its design and by their explicit consent (Hart, 1976; Lindemann \& Harbke, 2011 ). The more that teachers are aware of their own metacognitive processes in designing a contract grading model the better for all.

Other considerations that might go into implementing contract grading include a simple desire to be more fair when it comes to final grades since teachers are not uniformly consistent graders of writing quality, and since evaluations for grades are somewhat subjective, inconsistent, and both personally and socially constructed (Hart, 1974; Taylor, 1980; Cox, 2014; Elbow, 2006; Inoue, 2015, 2019; Kohn, 2013; Schwarz, 2020). A positive reason to consider implementing contract grading is that a number of teachers claim that contract grading helps students to focus on learning, and as a result become better writers, by removing their fear and anxiety about grading (Danielewicz \& Elbow, 2009), and yet another argument used to justify contract grading is that it fits an individualist epistemology (Hart, 1974; Newcomb \& Warmbrod, 1974; Taylor, 1980; Danielewicz \& Elbow, 2009; Elbow, 2006) as well as fitting into a social constructivist, or critical race theory epistemology (Inoue, 2015, 2019; Schwarz, 2020). Contract grading may be an attractive option because it works well to remedy the various traditional and modern pedagogical and epistemic problems and conflicts around assessment, and it 
accommodates the different ways that we use the English language, apart from sometimes outmoded monolingual models.

\section{Translingualism}

In American schools, students have traditionally been taught mostly standardized academic English varieties, which we should legitimately scrutinize in this day and age. Such standardized dialects work well for students that are experienced in these dialects, particularly when they are used in the home. For students with less experience, this can put them at a disadvantage, so It is important to consider the language background of the students that we teach. Gee (2012) explains how this affects students:

School is, as it is presently constituted, ultimately all about learning specialist varieties of language, in particular academic varieties of language connected to content areas. Some children bring early prototypes of academic varieties of language to school-prototypes they have learned at home. Some do not. (p. 16)

He goes on to explain:

This is because schools do not start the academic language acquisition process for these children - a process that has already started at home for other children. Rather, they teach these children to "read" only in the sense of being able to do phonics and dealing with the superficial literal meanings of words mostly in the vernacular. Poor children suffer the same sort of plight that someone who tries to pass French 4 without French 1, French 2, and French 3 does. This problem doesn't say much about the children's abilities, though it says a lot about the schooling system they are in. (p. 17)

This is not to say that a standard academic code has no place in our teaching--it does. However, ideas about what are standard dialects are subject to constant change as there exist many varieties of language, both within and outside of English, and many, if not most of us code switch 
regularly, so it is incumbent upon us to rethink and expand our understanding of the English language, especially in this modern world where it is normal to interact with language users across the globe in person or on social media. Gee (2014) explains how this is the case even when we exclude the larger world outside of the United States:

Actually, it's not one thing, it's many things. There are many different varieties of English. Some of these are different dialects spoken in different regions of the country or by different sociocultural groups. Some of them are different varieties of language used by different occupations or for different specific purposes: for example, the language of bookies, lawyers, or video game players. (p.14)

Thus, it is incumbent upon us to expand our understanding of what constitutes acceptable varieties of English used in academia as we assign and assess student writing with respect to dialects. In order to be more fair, it seems that we should embrace a translingual approach to language.

The translingual approach to language and writing addresses fairness by recognizing how the notion of an idealized English does not reflect the linguistic reality of many English language users attending colleges and universities, and this is also true with ESOL students who come from diverse language and dialect backgrounds (Cox, 2014; Gee, 2012; Lee, 2016; Matsuda, 2014; Horner, Lu, Royster, \& Trimbur, 2011; Ramanatham \& Atkinson, 1999). Translingualism has been assumed to mean different things. Sometimes it is seen as repudiating dominant dialects of the sort that Inoue $(2015,2019)$ criticizes as a white suprmacist variety, but this is typically not the case. Thus, Matsuda (2014) argues that it is incumbent upon us to define 'translingual':

"Over the last few years, I have reviewed numerous manuscripts submitted to major journals in the field, and while many of them mention translingual writing as necessary for their work, they often fail to define the concept or to use it consistently' (p. 479). 
Thus, translingual as used in this capstone hopefully reflects a description of language use that matches the reality of how language is used in this current era, as opposed to an ideal or prescriptive use. The way that the term languaging is explained by Lee (2016) helps illustrate this description:

The decision to use languaging is additionally significant. While the common expression "language use" suggests an ontological stability of language as a system that is used by a community of people, languaging represents an emergent process of social interaction that does not merely draw from "language" but constitutes the "language" through ways in which it is practiced by individuals" (p. 181).

Another way to explain translingualism is to understand what it is not, and Matsuda (2014) suggests that it is not an attempt to replace current standards:

The effort to draw a clear line between two intellectual movements often creates a false binary that masks their complexity, that stigmatizes the old and valorizes the new, making it difficult for anyone to side with the status quo (p. 480).

Thus, as I interpret Matsuda, translingualism is not an attempt to discredit the old (SAE) in favor of a new standard, but to recognize that how we use language is highly contextualized depending on many factors, such as the position of the writer, audience, community of practice, and the language most effective for communicating within this context, As Lee (2013) notes:

While we certainly should continue to legitimize language practices that have historically been marginalized, including elements of translingual writing that historically have been neglected in academic contexts, there is a fine line between what constitutes "translingual" and "monolingual" and assessment practices driven by a desire to promote linguistic social justice must avoid reifying a false translingual-monolingual dichotomy as a means of uncritically valorizing the translingual over the monolingual. (p.187)

In short, the varieties of language used, taught, and assessed in the classroom require that we deeply consider the purpose, audience, and rhetorical needs of the students. This does not 
necessarily require that we elevate nonstandard dialects or that standard dialects are assailed. We may need to recognize the legitimacy of both along a continuum..

From this discussion of contract grading, we see that there are numerous ways and reasons to consider implementing contract grading, whether to make grading easier, to focus on the writing process, or to establish a grading method that promotes fairness and equity with respect to diverse social, cultural, and language background (Elbow, 2006; Danielewicz \& Elbow, 2009; Shor, 2009; Gee, 2012; Inoue, 2014, 2019; Schwarz, 2020). Danielewicz and Elbow (2009) argue that contract grading takes a burden off teachers and students: "In short, we seek to reduce struggle by trying to make life easier for us as teachers and writing more pleasurable for students as writers" (p, 241). A number of teachers also acknowledge that attempts to evaluate writing quality are highly subjective and in practice are unequal (Taylor, 1980; Elbow, 2006; Danielewicz \& Elbow, 2009; Shor, 2009; Inoue, 2014, 2019; Schwarz, 2020). Such that at times, the reasons that one student earns an "A-" and another earns a "B+" seems to defy any concrete or objective measure of reason, and attempts to normalize the grading of student's papers against that of other student papers appears more as mysticism than science. For this reason, Schwarz (2020) calls for de-norming grading and uses contract grading without evaluating writing for grades: "Classroom assessment genres are full of arbitrary features that we often take for granted as necessary or 'just the way it is.' " (p. 31). Another reason for contract grading (especially suited to my own philosophy) is that contract grading can empower students, and is therefore student-centered since students have more input and freedom that hopefully leads to more student agency (Hart, 1975, Shor, 1999; Elbow, 1999). While, for others like Inoue $(2014,2019)$, contract grading is in part advancing the teachers political and social stance, which 
in essence joins writing instruction to a specific sociological lens of critical race theory. Shor (1999) considers writing as part of an exercise of democracy for his students, and Elbow (2009),

on the other hand, seeks to not politicize the classroom: Our approach would appear to be highly unpolitical and "uncritical"-_ideologically unaware" (p. 241). Thus, contract grading can be adopted for a variety of reasons or in conjunction with a range of ideologies.

\section{Contract Grading and ESOL Classes}

At many colleges and universities it is common for first-year writing classes to have native English speakers who speak multiple dialects of English, for example, African American Vernacular, Chicano English, etc., or dialects based on socioeconomic class and regional Englishes. In addition these classes may include one or more students who are bilingual, but have English as their dominant language (Shor, 1999; Cox, 2014; Inoue, 2016, 2019; Horner, Lu, Royster, \& Trimbur, 2011; Lee, 2016). There are times when these writing classes also include ESOL students as has been the case for the first-year writing class that I taught as a graduate teaching assistant at San Francisco State University. Thus, when referring to ESOL writing we should acknowledge that these students may attend writing classes more traditionally considered as native English speaking so it is important to think about these students in all college writing classes.

As indicated in the introduction, one of the motivations for this capstone is that there is relatively little discussion of contract grading with ESOL students. While the discussion of contract grading has been applied to writing classes, there are not many instances where it is applied to ESOL writing classes. However, contracts are not new to ESOL as TESOL scholarly 
literature abounds with robust discussions of contracts and autonomous learners (Sidhu, Kaur, \& Chan, 2011; Zhong, 2010). For instance, Sidhu, Kaur, and Chan (2011) describe autonomous learners as those "learners who understand what is being taught, are able to formulate their own learning objectives, are able to select materials, make use of appropriate learning strategies and monitor and self-assess their own learning" (p. 218). While learning contracts differ in some ways from contract grading as previously discussed, many of the objectives, motivations, and benefits of their use are shared in common with contract grading. For instance, the fact that they are both an agreement between the teacher and the students, that they both require some autonomy from students, and they both allow students more academic freedom since they require that the students take an active role in both the learning and its assessment. The common goal for each is the desire to involve students in their own learning process so that they can reap the benefits of that involvement. Then the question is, why not use contract grading in ESOL writing classes? and, what are the challenges?

Prior experience, including culture, and their effects on student beliefs may make contract grading difficult to accept for some ESOL students. Consequently, it is important to get to know, not only the background of our students, but also to learn about the students' culture and its belief systems as it pertains to education. Zhong (2010) makes this point clear in a study on Chinese learners: "However, I argue before promoting autonomous learning, it is essential to detect learners' beliefs" (p. 213). Some students expect teachers to not only test their learning, but to evaluate and direct their learning. However, this propensity may be stronger in individual students, and it still may be possible to teach students, who are initially resistant, to be 
comfortable with a more autonomous learning emphasis. For instance, Zhong (2010) found that only one of five Chinese students that he studied was comfortable with autonomous learning:

The significance that the participants placed on the role of exams may arise from their previous learning experiences in China where exams were usually high-stake. In other words, the test results played a vital role in their lives. For instance, they were used as the criterion for admission into university, applying for jobs and career promotions. Although they were in New Zealand, the influence from their previous learning still came into play. (Zhong, 2010, p. 216)

Some other characteristics that came from Zhong's (2010) study was that some ESOL students may need more teacher focus on grammar and spelling as it is important to keep in mind that ESOL students are likely putting in more effort to perfect their English language skills when compared to many native students, along with their writing skills. Additionally, contrary to what many might expect, some students indicate that pressure from the teacher benefits them as the students said that the pressure helps motivate them to revise and summarize their work: ...tests can give me some pressure. Humans are lazy by nature. But if I have tests, I will treat them seriously. The revisions before the tests had a big impact on me. They made a great difference.....if I revise before exams, I can perform better. Tests help you learn and give you some pressure to learn more. For me it works very well. (Shan, Int II). (Zhong, 2010, p. 215)

Thus, a teacher may need to be flexible as it may be necessary to employ contract grading for the majority of the students and let some students opt-out for a more traditional approach. This can be negotiated with the students at the beginning of the course, and it might be good to check in periodically with students to determine whether they want to switch methods. Students who prefer traditional grading can change their mind as also evidenced by Zhong (2010):

Apparently, Fei changed her belief about the role of exams in her learning in the new learning context. Exams were not the drive in her learning anymore. On the contrary, she 
was in control of her own learning. She knew how to plan and evaluate her learning. Her learning behaviour was not reactive anymore but proactive. (p. 216)

Therefore, the first step in adopting contract grading for ESOL students is to have a discussion with the students, explain contract grading, and get to know the students and their background. Then, be prepared to be flexible and perhaps allow students to opt-out on an individual basis, at least until they become more comfortable with contract grading.

Once students accept contact grading, it is clear that many of the same reasons that make contact grading desirable for native English speakers in first-year college writing classes, also apply to multilingual or ESOL writing classes, whether the goal is to promote more effective teaching and learning by focusing on the writing process, rather than grades. Or, whether your goal is to promote more fairness and equity around cultural and language diversity. It is important to discuss contract grading with students, and it is important for teachers to think through the problems and potential benefits of contract grading. For instance, how we apply and assess specific linguistic codes and their impact on questions of fairness and equity in our assessment practice. We need to acknowledge that privileged or dominant varieties of language come about as a result of power dynamics in societies, and that they are influenced by culture and other social forces that include the media and effects of academic norms. Such issues are not limited to American colleges or universities and will arise in any culture when a dominant majority fails to take into due consideration the needs of minorities. However, decisions about teaching and assessing linguistic codes are not simple as we must take into consideration how the students will use these linguistic codes in a variety of situations. One must consider the academic 
and occupational goals of students and the realistic attitudes of those employers outside of academia. As Lee (2016) argues:

Linguistic social justice ... thus cannot be reduced to simply inviting alternate discourse styles in academic, even high-stakes, writing without attending to the technologies placement testing, exit testing, common rubric scoring, among others - and stakeholders who decide when and where such discourse styles will be valued. (p. 176)

It may be appropriate to heed the once sage advice: "It is sometimes better to know the rules, and once you know the rules, then you can break the rules" (anonymous). And by doing so, thus creating new dominant dialects! We have no choice but to confront a problem that is compounded for ESOL learners who may have less intimate experience with the English language, and who may not fully understand the implications of these language choices. Thus, rather than thinking primarily about error correction, we need to explain to these students the various connotations of using English that might not be apparent to them as second language learners (Lee, 2017, p. 177).

A translingual orientation toward language teaching should not be limited to advocating for the linguistic rights of ESOL students alone. It is important to remember that certain "native speakers" of English, such as students who speak African American Vernacular English, and other dialects have historically been marginalized because of their language differences (Gee, 2012; Lee, 2014, Inoue, 2015, 2019). and thus the decision to teach a dominant academic code, a transgressive code, or perhaps some broader combination of codes may depend on the needs of the students and the context surrounding their writing, per Lee (2014):

Both the idealist and pragmatist positions represent well-intentioned desires to promote student learning, and it would thus seem that both can be considered inherently invested in the promotion of their own means to linguistic social justice. (p.179) 
Although, it is good to keep in mind that the notion of translingual writing is a work in progress, according to Matsuda, 2014), scholars who embrace it seem to share the following perspectives:

- English monolingualism is prevalent and problematic.

- The presence of language differences is normal and desirable.

- Languages are neither discrete nor stable; they are dynamic and negotiated.

- Practicing translingual writing involves the negotiation of language differences.

(Matsuda, 2014, p.479)

These perspectives highlight why the use of contract grading can be both beneficial and challenging for ESOL writing classes. It enables teachers to be more flexible in understanding the complexities and the dynamic nature of language, but sometimes the biggest challenge can be to convince the students. 


\section{Discussion}

Each teacher should, in my opinion, think deeply about how they design their classroom assessment, including whether and how to issue grades in the writing class. As has been shown, these assessment practices are often motivated from a desire to be fair in assessing students' writing, and also sometimes ideological considerations motivate the use of contract grading. However, determining what is fair and whether to apply ideology to contract grading are not decisions without consequences and should be carefully considered. There are certain questions that naturally arise, and that should be considered and addressed periodically. For instance: Is it in the students' or the teachers' best interest to eliminate grading that evaluates student writing? What do the students want and what role should their goals have in these decisions? Why are they in college? What major or occupational goal? Is it in the best interest of the student to advance the teachers' ideological worldview as part of the class curriculum? What is the role and the utility of teaching and addressing questions of grammar, academic register, and genre when teaching and evaluating writing? Some are questioning existing standards of academic writing, and yet ultimately, the result or pushing back against some standards might simply be that it may result in a new academic standard. What is the purpose of emphasizing first person, third person, or the use of personal pronouns in writing? These and similar questions we hope to have inspired into the discussion on contract grading as these are serious questions, and it is incumbent upon each teacher, or institution, to consider these questions when developing an assessment strategy for teaching college writing. These are important pedagogical and linguistic questions that have social and political ramifications, but most importantly, they have

ramifications for students. There have been demands to change many academic practices in the 
teaching of writing, for instance, those encapsulated in the statements from the Conference on College Composition and Communication (1974) Students' Right to their Own Language" and (2020) “This Ain't Another Statement! This is a DEMAND for Black Linguistic Justice!,” but such demands may not represent the wants or needs of many minority or Black students.

Colleges tend to become idealistic, sometimes at odds with students and the larger non-academic world. Thus, it is important to discuss these issues with other teachers and our students, and to give students a say in these matters.

In coming up with a contract grading strategy it helps tremendously to dive deeply into the academic literature and to consider the research and experiences of others. Thus, I take seriously the work of Elbow, Shor, Inoue, and all the others as they have contributed a great deal toward this discussion of contract grading and assessment. They have forced me to think deeply about the myriad of issues around teaching and assessing writing. Ultimately, teaching is about the students, so it is important to consider the needs of the students, whether it pertains to their goals as students, or their needs in relation to their language backgrounds--whether they are native English speakers or ESOL students. It is nearly impossible to ignore tradition entirely as we are shaped by our experiences, and as a native English speaker with an undergraduate degree in English, I can't ignore my training. However, part of that experience and training teaches me that the ideas embodied in translingualism reflect a more accurate view of language so that I must not accept my own languaging habits as universal and applicable to others. Thus, it is important to be aware of the context for which language is being used. To be fair to students, they must be approached as individuals, while also acknowledging the social context of learning. Ideology and particular lenses that we use to understand our world should help expand our 
understanding of things, but if we are not careful they can instead narrow our understanding. Teachers should consider their student's language background, their choice of academic major, and their future occupational aspirations as we make choices with respect to teaching and assessing writing. The language needs of a student seeking a degree in the music of Jazz, and that of a student seeking a career in journalism at a national paper or magazine can differ considerably. Some mastery of a standard or dominant code of English might empower a student, as much or more than it disadvantages the student. It really seems to depend on how we analyze our relationships with each student, and how we balance trying to provide students with what they want and what they need for their benefit. It requires that we observe and listen well to students. It requires being flexible.

As for ideological considerations, while I appreciate the views of each of the scholars that I examined, I mostly agree with Danielewicz and Elbow (2009) as I wish to avoid politics in the classroom. However, that does not apply to the political engagement of students who should be encouraged to bring their own views about politics into the classroom. In facilitating the learning of writing, I also agree with Shor (2009) that students should take whatever stance they hold toward politics in the writing classroom. Part of their journey as students is to explore and create their own ideological perspectives as part of their college experience. One of the motives for me to get into education was a concern for students to experience learning as a process of exploration through various theories and life experiences. I hope that students will learn to explore and see the world through many lenses, rather than a particular lense. I never respected the notion of students as receptacles for me, as an authority, or for society, to indoctrinate them into our ideologies. Contract grading seems well suited toward the flexibility of both language 
and ideology for teachers who wish to facilitate the learning of students. I appreciate the scholarship of Inoue $(2015,2019)$, who has deeply explored the subject of assessment, and though I do not agree with him in many ways, I appreciate how his views forced me to think much more deeply than I otherwise might have about all of these topics. 


\section{Conclusion}

Contract grading seems as though it should be well suited for college ESOL and multilingual writing classrooms. The main advantages of adopting contract grading are in the way that it involves students in their own education process so that they think about their learning and their writing metacognitively, and in how contract grading takes the traditional emphasis off of grades and puts the emphasis on the actual writing or process (some might say learning). Teachers should approach contract grading with a great deal of flexibility since there may be resistance to it due to how it is nontraditional. Thus for ESOL students, it is important that teachers learn about their students educational background and any cultural practices for which they are accustomed, and that teachers discuss contract grading with students so that they can ascertain the students' attitudes and feelings toward contract grading. It will be interesting to see whether contract grading takes off with TESOL, and to see how ESOL teachers might approach contract grading as time goes on. So we hope to see an increase in TESOL teachers' discourse on contract grading and it becoming part of their community of practice in the future. The importance of autonomous learning and learning contracts are known, discussed, and researched in TESOL, so contract grading, given that is similar and yet newer to TESOL, might require different approaches than some of those used in composition and other disciplines. It is my hope to be reading more about contract grading soon in ESOL and multilingual writing classes. 


\section{References}

Brenner, P. S., Serpe, R. T., \& Stryker, S. (2014). The Causal Ordering of Prominence and Salience in Identity Theory: An Empirical Examination. Social Psychology Quarterly, 77(3), 231-252. https://doi.org/10.1177/0190272513518337

Brooks, D. (2020). Opinion | The Age of Coddling Is Over. The New York Times. (April 16) https://www.nytimes.com/2020/04/16/opinion/coronavirus-medical-training.html

Cox, Michelle. (2014 )“'In Response to Today’s 'Felt Need': WAC, Faculty Development, and Second LanguageWriters.” WAC and Second Language Writers: Research Towards Linguistically and Culturally Inclusive Programs and Practices.

Conference on College Composition and Communication. (1974) Students' Right to Their Own Language. Spec, issue of College Composition and Communication 25: 1-32.

Conference on College Composition and Communication. (2020). "This Ain't Another Statement! This Is a DEMAND for Black Linguistic Justice!” Conference on College Composition and Communication, cccc.ncte.org/cccc/demand-for-black-linguistic-justice.

Danielewicz, J., \& Elbow, P. (2009). A Unilateral Grading Contract to Improve Learning and Teaching. College Composition and Communication, 61(2), 244-268. JSTOR. 
Elbow, P. (1999). Individualism and the teaching of writing: Response to Vai Ramanathan and Dwight Atkinson. Journal of Second Language Writing, 8(3), 327-338. https://doi.org/10.1016/S1060$\underline{3743(99) 80120-9}$

Elbow, P. (2006). Do we need a single standard of value for institutional assessment? An essay response to Asao Inoue's “community-based assessment pedagogy.” Assessing Writing, 11(2), 81-99. https://doi.org/10.1016/j.asw.2006.07.003

Elbow, P. (2014). "Personal Writing” and "Expressivism” as Problematic Terms. In T. Roeder \& R. Gatto (Eds.), Critical Expressivism: Theory and Practice in the Composition Classroom (pp. 1532). The WAC Clearinghouse; Parlor Press. https://doi.org/10.37514/PER-B.2014.0575.2.01

Gee, J. P. (2012). Situated Language and Learning A Critique of Traditional Schooling. Florence: Taylor and Francis.

Haidt, J. (2012). The righteous mind: Why good people are divided by politics and religion. New York: Pantheon Books.

Hart, D. (1975). A Comparison of the Contract Plan and the Daily-Recitation Plan of Learning for Effects in the Cognitive and Affective Domains in a High School Poetry Class. 157. 
Horner, B., Lu, M.-Z., Royster, J. J., \& Trimbur, J. (2011). Language difference in writing: Toward a translingual approach. College English, 20.

Huot, Brian. (Re)Articulating Writing Assessment for Teaching and Learning. Utah State UP, 2002.

Inoue, A. B. (2004). Community-based assessment pedagogy. Assessing Writing, 9(3), 208-238. https://doi.org/10.1016/j.asw.2004.12.001

Inoue, Asao B. (2015). Antiracist Writing Assessment Ecologies: Teaching and Assessing Writing for a Socially Just Future. WAC Clearinghouse and Parlor P.

Inoue, Asao B. (2019) Labor-Based Grading Contracts: Building Equity and Inclusion in the Compassionate Writing Classroom. WAC Clearinghouse and UP of Colorado.

Kinzie, J., Palmer, M., Hayek, J., Hossler, D., Jacob, S. A., \& Cummings, H. (2004). Fifty Years of College Choice: 76 .

Kohn, Alfie. (2013). The case against grades. Counterpoints, 451, 143-153

Lee, J. W. (2016). Beyond Translingual Writing. College English, 79(2), 174-195. 
Lindemann, D. F., \& Harbke, C. R. (2011). Use of Contract Grading to Improve Grades Among College Freshmen in Introductory Psychology. SAGE Open, 1(3), 2158244011434103. https://doi.org/10.1177/2158244011434103

Matsuda, P. K. (2014). The Lure of Translingual Writing. PMLA, 129(3), 478-483.

McWhorter, John (2021). The Elect: The Threat To A Progressive America From Anti-black Antiracists. https://johnmcwhorter.substack.com/p/the-elect-neoracists-posing-as-antiracists

Mullen, Abby (2020). Revising Contract Grading. http://abbymullen.org/category/uncategorized/

Newcomb, L. H., \& Warmbrod, J. R. (1974) The effect of contract grading on student performance. Ohio State University, 1-15

Ramanatham, V. \& Atkinson, D. (1999). Individualism, academic writing, and ESL writers. Journal of Second Language Writing, 8 (I), 45-75. https://www.academia.edu/35993559/Individualism_academic writing and ESL_writers

Schwarz, V. M. (2020). (De)Norming Classroom Merit: Grading Contracts as an Assessment Genre [Ph.D., The University of Wisconsin - Madison]. http://search.proquest.com/docview/2441241897/abstract/E7A0AABA7BF840B6PQ/1 
Sidhu, G.K. \& Kaur, S. \& Chan, Y.F. (2011). Developing learner autonomy in the ESL classroom through the use of learning contracts. Pertanika Journal of Social Science and Humanities, 19 (1), $217-232$.

Shor, I. (2009). Critical pedagogy is too big to fail. Journal of Basic Writing, 28(2), $6-27$.

Shor, I. (1999). What is Critical Literacy? Journal of Pedagogy, Pluralism, and Practice, 1(4), 2.

Taylor, Hugh. (1971). Student Reaction to the Grade Contract. The Journal of Educational Research, 64(7), 311-314.

Taylor, Hugh. (1980) Contract Grading. http://archive.org/details/ERIC_ED198152

Yancey, K. B. (1999). Looking Back as We Look Forward: Historicizing Writing Assessment. College Composition and Communication, 50(3), 483. https://doi.org/10.2307/358862

Yancey, K.B. (2015). 3.2 Writers' histories, processes, and identities vary. In Adler-Kassner, L. Naming What We Know: Threshold Concepts of Writing Studies (pp 52-54). University Press of Colorado. 
Yarber, W. L. (1973). A Comparison of the Relationship of the Grade Contract and Traditional Grading Methods to Changes in Knowledge and Attitude During a Venereal Disease Instructional Unit [H.S.D., Indiana University]. http://search.proquest.com/docview/302660615/citation/A25D55B147EB4391PQ/1.

Zawacki, Terry Myers, \& Cox, Michelle. (Eds.). Fort Collins, CO: TheWAC Clearinghouse and Parlor Press: 2014, 299-326. (Available at http://wac.colostate.edu/books/12/)

Zhong, Q. (2010). The Effect of Chinese ESL Learners' Beliefs on their Autonomous Learning. Studies in Self-Access Learning Journal, 1 (3). pp. 212-225 